\title{
Commentary about multiple submissions
}

\section{Michael Oppenheimer ${ }^{1} \cdot$ Gary $_{\text {Yohe }}{ }^{2}$}

Published online: 12 August 2019

(C) Springer Nature B.V. 2019

A single author submitting the same or a very similar manuscript, alone or with others in whatever order, to more than one journal so that the manuscripts are under simultaneous consideration, is violating long-established academic norms. There are consequences for such actions.

For example, when we, at Climatic Change, find irrefutable evidence that the same manuscript with only minor adjustment but with the same author identified anywhere in the author list, has been submitted to Climatic Change and another journal, we will automatically send a rejection letter.

Moreover, we will alert the other journal (or two or three) about what we have discovered; and we have every reason to expect that the editors of those journals will follow our lead.

We will inform the author of the reasons for our actions and, depending on circumstances, also inform their immediate supervisor, such as their dean, at their home institution.

Of course, submission of such a manuscript to a second journal after an initial submission has been rejected elsewhere is unobjectionable. The issue at hand refers to manuscripts under simultaneous consideration. We acknowledge that borderline cases arise. Sometimes they are even genuine errors of miscommunication among co-authors. In all of these situations, the author as well as the editor of the other journal will be consulted without impunity.

How likely is it that we will find out that a submission to Climatic Change closely resembles a submission elsewhere? We believe the answer is "very high,"

How so? For any specific scholarly topic even in a field as diverse as climate change, the pool of potential reviewers is not large. We usually invite as many as six scholars to review (hoping that $50 \%$ will accept the invitation). It follows that our invitations will frequently overlap the invitations from other journals. For a single submission on a particular topic, therefore, it is highly likely that one expert will be invited for such a paper more than once (from different journals). We are confident that any reviewer who sees the same paper from two or more journals will immediately contact us; at least, that has been their response over the past several years.

Michael Oppenheimer omichael@princeton.edu

1 Princeton University, Princeton, NJ, USA

2 Wesleyan University, Middletown, CT, USA 
Meanwhile, Springer's everyday plagiarism screening procedures are applied to the majority of the journals in its stable. It follows that submissions to most journals in their stable (and there are thousands) are subjected to word by word comparisons with not only published or accepted papers, but also with submissions to multiple venues. High scores raise flags that are taken very seriously.

With very high confidence, therefore, we will discover any set of two or three submissions of roughly the same manuscript to multiple venues. In that case, the submission

(1) Will be rejected immediately by Climatic Change and

(2) Will likely be rejected elsewhere on the basis of our communications with other editorial teams.

Furthermore, it is conceivable that if we or the other journal notify the author's institution, the latter may take disciplinary action.

To summarize, from the perspective of a journal that takes risk management very serious (thanks to our founder and others), the personal consequences of knowingly violating this historic behavioral norm by submitting a manuscript to Climatic Change and to some other venue at the same time are potentially very high. The likelihood of being detected is also very high. So, in our vernacular, the risk associated with this behavior is enormous.

Publisher's note Springer Nature remains neutral with regard to jurisdictional claims in published maps and institutional affiliations. 